\title{
The Mystery of Symbolic Culture: \\ What fitness costs? What fitness benefits?
}

\author{
Jean-Baptiste André \\ Département d'Etudes Cognitives, Ecole Normale Supérieure, Paris \\ Nicolas Baumard \\ Département d'Etudes Cognitives, Ecole Normale Supérieure, Paris \\ Pascal Boyer \\ Depts of Anthropology and Psychology, Washington University in St. Louis.
}

\begin{abstract}
:
In contrast to language or technology, many "symbolic" cultural phenomena do not seem to confer immediate fitness benefits. Standard approaches to cultural evolution in this domain focus on the recipients or consumers, which does not explain why these phenomena emerge. As a solution, we propose to consider the fitness costs and benefits incurred in producing behaviors or information that become widespread in a social group. Taking the producers' perspective helps explain otherwise puzzling features of many kinds of cultural phenomena, such as artistic activities, sports, religious representations, or even moralistic norms. Considering the producers' as well as the consumers' benefits is crucial to generating precise hypotheses about the psychological adaptations that underpin cultural evolution.
\end{abstract}

\section{Keywords:}

Cultural evolution; Symbolic culture; Fitness costs; Social evolution theory; Evolutionary psychology 


\section{The Mystery of Symbolic Culture: What fitness costs? What fitness benefits?}

Evolutionary models of human culture must address two fundamental questions, Why do humans create cultural materials at all? and, Why do humans create these particular forms of cultural materials? We contend that some standard approaches to cultural evolution are insufficient to address these two questions, because they mostly focus on consumption rather than on the production side of cultural phenomena.

That is particularly clear in what we will call, for lack of a better term, the domain of "symbolic culture", that includes art, narratives, religious representations, games, sports, ethnic ideologies, rumors and superstitions, moral norms and codes, and many social conventions. This obviously is a disparate domain, usually identified by cultural anthropologists by its lack of practical use [1] - as well as the occurrence of beliefs that are (only apparently) irrational [2, 3].

Here we mostly consider the fitness aspects of this problem. One common feature is that these different cultural phenomena seem difficult to explain in terms of fitness advantages. Why do humans compose and hear narratives? Why create and abide by culturally specific, arbitrary conventions? Why spread and transmit rumors? A common answer is that many such products are "cheesecake for the mind" [4], or that they invade minds as viruses and parasites invade bodies [5]. Those are insufficient explanations, if we want to understand why cultural objects of this kind are produced at all. From an evolutionary perspective, some agents must have a fitness advantage in creating symbolic culture, as there is no such thing as free cheesecake.

\section{Limitations of the consumption view}

To explain trends in cultural evolution in this symbolic domain, evolutionary anthropologists generally focus on the minds of the receivers (see Box A for details). For instance, the fact that musical traditions, however diverse, abide by similar tonal

principles $[6,7]$, is explained by properties of the human auditory cortex and 
memory; the most successful stories follow a limited set of narrative formats [8, 9], because they satisfy a human motivation to know and understand the social lives of others; people construe ethnicity in terms of innate properties of individuals [10], because of our intuitive essentialism about natural categories; and so forth.

However, this exclusive focus on consumption does not provide any explanation for the large investment in the production of those behaviors or artifacts that may become widespread in a group. For instance, listening to Mozart or the Beatles is indeed riveting (on the consumption side), but that does not by itself explain the thousands of hours of training invested by composers and performers. In many domains of cultural knowledge, production is less dramatically costly but still begs for an explanation. Why do people expend cognitive resources-creating complex stories, recipes for dealing with misfortune, and ideas about gods and spirits?

Addressing these questions amounts to focusing on production as well as consumption.

\section{Production is not consumption: different mechanisms, different interests}

Production and consumption differ. First, obviously, they most often consist of different behaviors that engage different sets of capacities and preferences compare musical performance and musical enjoyment, story-telling skills and attention to narratives.

More important, production and consumption generally engage different interests. The pleasure that an audience derives from listening to Mozart or the Beatles does not in itself constitute a benefit to the composers and performers. Conversely, the benefits that shamans, healers or priests may derive from their knowledge are not directly aligned with the benefits - or costs, as a matter of fact for their customers. As a result, the fact that a cultural item is useful or not for its consumers does not in and of itself explain its success, or lack thereof. So, to explain the existence and nature of symbolic culture, one must explain why producers spend time and energy producing them in the first place.

A convenient framework to describe and understand the evolutionary logic of cultural production is social evolution theory [11]. The production of cultural information is a social behavior, whereby an individual, the producer, acts upon another individual, the consumer. Cultural production can therefore be classified 
into four categories according to its effects on the reproductive success of both the producer and the consumer $[11,12]$, see Table 1.

\begin{tabular}{ll|c|c|}
\multicolumn{1}{c}{} & \multicolumn{2}{c}{ Effect on recipient } \\
\cline { 3 - 4 } Effect on actor & Positive & Positive & Negative \\
\cline { 3 - 4 } & Negative & Mutualism & Selfishness \\
\cline { 3 - 4 } & & Altruism & Spite \\
\cline { 3 - 4 } & &
\end{tabular}

Table 1. Types of social behavior, after Hamilton [11].

In the following, we consider these different types of social effects and show how, in each case, the interests of producers and consumers interact to explain the features of symbolic culture.

\section{Different configurations of producer's and consumer's interests}

\subsection{Altruistic production with indirect benefits}

The production of symbolic culture is altruistic if it has a negative effect on the direct fitness of the producer and a positive effect on the direct fitness of the consumer [13]. The producer can ultimately benefit only if the consumer's benefit constitutes an indirect fitness benefit, that is, if the consumer is a genetic relative. Social evolution theory predicts that altruistic cultural production will be mostly directed at close kin, as a function of perceived relatedness.

Cultural examples. Parents the world over engage in pedagogic interaction, whereby infants spontaneously attend to generic information, when caretakers attract their attention with specific communicative cues [14]. Acquiring general knowledge of the world is beneficial to infants and in turn indirectly to their genetic relatives. In a similar way, infant-directed singing is universal [15]. The infant benefits from sleep and reassurance, and it is also in the parent's genetic interest to promote their offspring's good health. 


\subsection{Selfish production: conflict and manipulation}

The production of cultural information is termed selfish if it has a positive effect on the fitness of the producer and a negative effect on the fitness of the consumer. The producer has a direct interest in producing cultural information but this production generates costs for the consumers. The interests of producers and consumers are not aligned, so that there is an evolutionary conflict between them. In this case, to obtain her benefit, the producer must manipulate the consumer, i.e. she must use the fact that the consumer does not have a perfect ability to filter information.

Cultural examples. We usually identify some aspects of symbolic culture as mostly manipulative. That is for instance the case for those religious "cults", whose leaders extract resources (labor, money, sexual services, etc.) from group members [16]. But the producer/consumer asymmetry also extends to less dramatic cases. Consider for example religious activities in small-scale societies. Notions of spirits and ancestors are attention-grabbing, which explains people's interest [17]. That much accounts for the consumption side. But we also know that in all human societies there are specialists such as diviners, shamans, etc. who produce most of the current religious representations and offer religious goods and services, in the form of rituals, amulets, incantations, etc. [18, 19]. The rituals and other activities promoted by these specialists do not generally bring much benefit to the consumers, and may indeed be costly in some cases. For producers by contrast, they are the source of social status, material resources, and prestige that often translate into direct fitness benefits. This amounts to a manipulative interaction, to the extent that there is no advantage for the consumers (this of course is an empirical question, and, is case specific).

\subsection{Mutually beneficial production}

The production of cultural information is mutualistic if it has a positive effect on the direct fitness of both producer and consumer [11, 20]. Just like mutualistic cooperation in general, mutualistic cultural production can take place for two distinct reasons. (1) It can benefit both the consumer and the producer in an automatic manner; (2) The producer can derive a benefit contingently, through a positive response of the consumer, a mechanism called reciprocity (in a broad sense 
of the term), conditional cooperation, or sometimes "enforcement" [20]. We consider these two possibilities in turn.

\section{(a) Mutualistic cooperation with automatic benefits}

Producing a cultural item that is useful to a consumer benefits automatically the producer if they have a common interest. The alignment of producer and consumer interests plays a significant role in culture in cases where the behavior produced is used by the consumer as an honest signal about the quality of the producer. That is the case in sexual selection. The preferences of the consumer (e.g. females) create a selection pressure for specific traits, capacities and behaviors in the male producer $[21,22]$, and both sides benefit as long as the signal is honest rather than manipulative.

Cultural examples. Signaling of this kind may provide a motivation for the production of cultural objects. A good illustration is the invention of sport, i.e., of rule-bound public displays of physical qualities, found in the most diverse cultural environments, with a clear gender imbalance in most non-modern cultures [23]. Sportive activities generally advertise the physical qualities of individual males or coalitions of men, including heritable qualities like coordination, explosive strength and dominance [24]. The fact that precise and constraining rules govern these behaviors turns possibly multi-factored differences between individuals into clear rankings that affect reproductive fitness [25]. In that sense, sports provide a functional equivalent of courtship displays. With similar goals, ritual ceremonies may include sport-like displays- consider for instance the famous Melanesian land dives, the (highly dangerous) ancestor of bungee-jumping, used in Pentecost and other islands as a demonstration of male warrior-like qualities [26].

\section{(b) Mutualistic interaction with conditional cooperation}

In most cases, producers do not automatically benefit from their production but eventually gain nevertheless through an exchange with consumers. The possibility of cooperation based on conditional exchanges, in humans, dramatically expands the range of situations in which individuals can benefit from producing new pieces of information, because it allows the value of cultural information to consumers to eventually spill over to producers. 
Cultural examples. There may be mutual advantages for both producer and consumer, in many cultural domains usually described only from one side of the interaction.

Consider "traditional" pre- or para-scientific forms of medicine. Apart from some actually effective cures, based e.g., on empirical knowledge of plants, it includes a large number of activities with no positive (and often some detrimental) effects on physiology, as in the widespread practice of bloodletting. This also applies to early Western medicine, which until the beginning of the $20^{\text {th }}$ century had very limited therapeutic efficacy. In evolutionary models, this has been mostly explained from the consumers' standpoint. But we should add that there are benefits for producers, as specialists in traditional medicine accumulate reputational advantages (with consequent fitness gains) from the patients' belief in their efficacy. In fitness terms, one could describe this interaction as (sometimes) mutually beneficial. Producers gain reputation while consumers, given pervasive placebo responses to medication, observed in both modern and traditional medical contexts [27] also receive potential benefits (although these are not exactly the benefits promised by the producers).

In a very different domain, there seems to be mutualistic advantages in the creation and transmission of conventional norms, in domains as diverse as market interactions, children's games, highway regulations and dress codes. Usually, we consider that conventional norms provide advantages to consumers. Given that large domains of social interaction include (or consist in) coordination games, the existence of arbitrary coordination points (e.g., that a handshake is done with the right hand) is to the consumers' advantage - a point emphasized in conventional accounts of norms $[28,29]$. But that is also why there is an advantage in providing such norms when they are absent, and (more relevant to actual social interaction) to maintaining norms against possible deviations, either instigated by interested parties, or simply as the result of entropy in communication. Surprisingly, this logic may also apply to constraining or coercive norms, as there may be advantages in both imposing the rules and abiding by them (see Box C).

\subsection{Spiteful production}

For the sake of completeness, we must mention the situation in which the producer pays a cost in terms of direct fitness in order to produce cultural 
information that manipulates the consumer to his detriment. Such spiteful behaviors can only be favored by natural selection if they have a positive effect on the producer's indirect fitness [30,31]. This situation is probably very rare, however, and does not play a structuring role in cultural evolution.

\subsection{Different fitness paths in the same domain of cultural products}

Note that these pathways can be combined. Above, we mentioned some typical examples for each configuration of interests, for the sake of illustration. But a domain of cultural production may be favored by distinct fitness dynamics in different situations. There may be a large element of sexual selection in the production of music, art and narratives, but in some cases musical performers extract resources from consumers, so that the manipulation dynamic is the relevant one. There may also be situations in which there are actual advantages for the consumers of art and fiction, so that the dynamic is a cooperative one. To take another example, traditional medicine may be considered as mostly exploitative, but inasmuch as it delivers advantages it could be sustained in cultural evolution by a cooperative equilibrium. Which of these evolutionary dynamics is relevant, for each cultural product, is of course an empirical matter.

\section{Producers' interests explain properties of symbolic culture}

In our view, seeing cultural items in terms of producers' interests may generate substantive hypotheses about the observed general features of some cultural products.

Consider some recurrent themes of the religious traditions before or outside organized, doctrinal religions typical of state societies [32]. In small-scale communities, religious representations focus overwhelmingly on the prevention or palliation of misfortune, which people see as caused by spirits, gods, ancestors or witches. From the consumption standpoint, these notions are culturally transmitted to the extent that they fit evolved expectations of potential threat in human minds [33]. Now looking at the production side, it is remarkable that in most societies there are specialists in the production of such representations [19, 34], whose interests may explain the focus on threats and prevention. Precaution psychology is a specialized cognitive system [35]. When precautionary information is deemed plausible, it is generally not put to the test, providing a niche for claiming expertise 
without delivering valid information, which may explain why individuals are motivated to engage in such activities. Only some people manage to convince others that they are qualified to interact with potential threats as regards gods and spirits the frequent use of trance is a signal of such capacities [19]. Winners in this game receive benefits in reputation and social support.

In the domain of artistic production, too, producers' interests may account for some properties of cultural products, beyond what is explained by a consumption model. In most human societies, some people are strongly motivated to produce sculpture, music or painting. This creates, even in small-scale communities, a competition between individuals that leaves only some individuals as recognized artists with a valuable contribution, which requires special capacities but also, in most cases, long training and sustained effort. Against these costs, groups deliver reputational and material benefits to the recognized artists, which would explain the motivation to engage in such activity. This also explains why the products have to be designed to advertise those special qualities that make the artist uniquely qualified. For instance, visual arts are generally designed to signal agency, that is, the fact that they exist because of a creator's intentions [36]. Also, in most traditions painting and sculpture must signal both a) what they are about, what the representational intention was, and b) that they are very difficult to produce, creating a "sweet spot" with e.g., obviously skilled figurative representations as a preferred genre [37]. In music, too, these constraints are at work, which would explain why most successful musical genres remain close to intuitive tonal expectations (signaling to listeners that it is not random), while delivering anticipation and surprise (signaling the unique skills of the musician) [7], see also [38].

In this sense the cheesecake metaphor is partly appropriate, as it suggests that producers of cultural objects, just like pastry chefs, need to be attuned to the evolved preferences of consumers. The metaphor becomes misleading, however, in that the nutritional benefits of super-stimuli like cheesecake are not needed in the modern world, and come with detrimental side-effects. To the contrary, we argue that in many cases cultural production occurs and is sustained, because it confers actual advantages to consumers as well as producers - more akin to healthy food than to unnecessary sweets.

Considering the producers' interests raises the question of the adaptations involved in producing the producers' fitness advantages. The present argument does 
not entail that we should postulate specific adaptations for the production of shamanism or tonal music or moral norms. But it does suggest that we should consider what specific psychological adaptations are required, so that individuals may intuitively consider the potential fitness benefits of such activities. Only specific empirical research, in these various domains of culture, can address this question, as behavior by itself is not transparent evidence for the psychological mechanisms that produce it $[39,40]$. But such research cannot even start, unless we recognize that there are potential fitness benefits to the behaviors that lead to cultural transmission.

\section{5. $\underline{\text { Conclusion }}$}

Clearly, the domain of "symbolic" culture is not a proper scientific domain - the term only denotes the apparent difficulty in explaining a great variety of cultural phenomena in terms of practical goals or fitness benefits. Indeed, we showed that there may be very different evolutionary dynamics at work in different situations.

Here we outlined three major pathways in the creation of symbolic culture apart from the probably minor altruistic pathway, whereby individuals create, e.g., lullabies or shelters for the benefit of their kin. (1) In a manipulative (genetically selfish) pathway, producers utilize for their own benefit some consumers' vulnerabilities, e.g., creating religious cults or manufacturing recreational drugs. (2) In a cooperative form of signaling, some producers may emit honest signals of their cognitive capacities, as a proxy for the genetic qualities under sexual selection. (3) In the mutualistic pathway, consumers and producers jointly receive fitness advantages, e.g., in producing norms or increasing the probability of success of collective action.

These models naturally extend to modern conditions, in which most cultural production and consumption in large-scale societies consists in contract-based market transactions for songs, paintings, novels, etc. Market conditions of course result in distinct trends of cultural evolution, very different from those observed where direct physical co-presence is required [41]. In particular, the amplitude and speed of diffusion are dramatically different from those observed in small-scale communities [42]. But the logic of fitness advantages remains the same. 
Only empirical evidence can adjudicate, which of these pathways is more appropriate as a model for specific situations of cultural production and consumption. But in all these domains, the focus on producers' as well as consumers' fitness benefits helps us understand what cognitive capacities are under selection, which in turn suggests new hypotheses to explain the particular features of successful cultural products.

We argued that symbolic cultural products are not or not just by-products of the human mind's architecture but should also be considered as direct products of other minds, which like any other behavior should be considered in terms of fitness.

Culture is not some external object that acts on humans. Rather, individuals have an impact on others through their symbolic production. Culture is not "transmitted" but humans use other people's productions (beliefs, tools, buildings) to further their own goals, which sometimes (but not always) leads to transmission and (rarely) in cumulative progress. 


\section{BOXES}

\section{Box A. Models of cultural evolution: the consumers' side}

The study of cultural evolution has known a spectacular development in the last twenty years, as evolutionary anthropologists applied formal quantitative models to the available evidence [43, 44], for instance phylogenetic techniques in the study of language families [43, 45]. What explains the particular trends described by such models? Proposals are diverse in this matter and the field is subject to substantial theoretical debates.

These proposals differ in terms of psychological adaptations they describe as underpinning cultural evolution.

At one end of the spectrum, dual inheritance theory [46] considers that individuals acquire social information on the basis of minimal heuristics, mostly akin to some form of imitation, and that the selection of materials to imitate is mostly sensitive to properties of the sources of information and its diffusion, and less so to the content of the information transmitted. For example, these theories attach great importance to simple heuristics such as conformist-bias (imitation biased by the relative frequency of a cultural item) or prestige-bias (imitation biased by the general social prestige of its bearer) [47].

At the other end of that spectrum, cultural attraction theory or epidemiology of culture $[48,49]$ considers that the acquisition and reconstruction of cultural information in individual minds is governed by numerous domain-specific capacities and preferences, such as, e.g., intuitive psycholody, intuitive biology, coalitional psychology, moral intuitions, etc. - see also [39]. The framwrork emphasizes the key role of the individuals' evolved abilities to modify, compare and combine different sources of information, to create recurrent representations in a community.

Many other models of cultural evolution are positioned between these extremes on the spectrum. For example, models proposed by Lehmann and Feldman [50] consider relatively crude and content-free heuristics of social learning, whereas Enquist et al. [51] considers finer-grained, content-biased learning mechanisms. In other models, a specific description of the psychology of learners is required for specific domains. Language evolution for instance can be described as resulting 
from iterated learning, in which Bayesian agents use the available evidence to adjust the probability of grammars [52]. These models show that the cultural evolution of language towards increasingly learnable grammars is highly dependent on the learners' psychological priors [53], which is confirmed by studies of artificial cultural transmission in the lab [54].

A common feature in all these models, beyond the differences, is the common assumption that we should first and foremost consider characteristics of the receivers or consumers of cultural information, in order to explain patterns of cultural evolution.

\section{Box B. "Cheesecake" and cultural "viruses": the limits of analogies}

Why do people spend time listening to music or stories? Why do they believe in supernatural agents, magic or traditional medicine? In some domains, one may argue that the consumer benefits. For instance, fiction may be understood as training for social interaction $[9,55]$. Visual aesthetics may train perceptual systems to relevant aspects of the natural world [56]. But in many other domains of culture, that is simply not the case. It seems difficult to explain the cultural spread of e.g., religion, horror movies or pornography, in terms of consumer fitness.

That is why such cultural items are often described as "cheesecake for the mind" [4] or mental viruses and "memes" [5]. For instance, because humans are motivated by parental investment, their nurturing instincts can be parasitized by kittens and puppies [57]; because humans are socially vigilant, they would be attracted to the notion of witches described in the same terms as predators [58].

The use of terms like "virus" or "parasite" illustrates what is missing here. In biological evolution, we must study the fitness of both host and parasite to understand their interaction, construed as an evolutionary conflict between sophisticated immune systems, on one side, and sophisticated mechanisms to escape such systems, on the other. So, if we consider some cultural information as informational parasites, we should address the question: Who benefits? Whose brains have been shaped by natural selection to be willing and able to produce information perfectly suited to get into people's minds, often against their interests?

Just as there always remain biological parasites capable of bypassing their hosts' immune systems, there always remains a certain amount of harmful cultural 
information that consumers are not able to filter out. So cultural "parasitism" occurs when some individuals invest brain power, effort and resources to find the right way to divert another brain's attention, e.g., from fitness relevant stimuli like human speech towards artificial stimuli like musical sounds. So-called cultural viruses are the products of individual minds trying to achieve effects on the minds of others (getting others' attention, signaling some qualities, manipulating others, sending some information, etc.) for their own benefit.

\section{Box C. Could constraining norms be an example of cooperation?}

Norms are often described as external to individuals, as sets of rules imposed on them. But norms are created and (more often) re-formulated and upheld by particular individuals who may derive benefits from the widespread adoption of the norm.

Consider for instance norms related to common pool resources, such as pastures, fisheries, canals, etc. In many societies, very specific norms regulate access to these resources, and violators are punished either formally and informally [59]. From a consumer's standpoint of view, these rules may seem coercive. However, such norms may constitute a standard example of mutualistic interaction with conditional cooperation. Individuals contribute to the enforcement of the norm (through time or resources given to some institution) in exchange for a higher level of cooperation from their partners. Here, norms instantiate second-order cooperation, i.e., a cooperative interaction that makes another (first-order) cooperative interaction more efficient. For instance, the members of Indonesian rotating credit associations produce and enforce norms regarding their meeting (e.g. weekly meetings are mandatory, they always take place at the same time, at the same place) because regular meetings facilitate the monitoring of the members of the association [6o]. In line with reciprocity theory, the most stable cultural norms regulating common pool resources are based on considerations of proportionality and fairness, [61]..

The same point can be made for norms regulating sexuality. From the customers' viewpoint, puritanical norms may appear essentially coercive to individuals. Why would they adopt a restrained lifestyle, depriving themselves of 
easy sex and drugs? However, if we take the producers' standpoint into account, puritanical norms may be, under certain circumstances, mutually advantageous. They increase the cost of sexual promiscuity, making it more advantageous to engage in stable pair-bonding and parental investment, for both men (reduced risk of cuckoldry) and women (reduced risk of desertion). So it becomes advantageous for individuals in such a situation to produce and enforce norms regulating pornography, alcohol consumption, abortion, pre-marital sex or masturbation [62, 63]. Consistent with this interpretation, puritanical or restrained norms are more likely to occur in societies where stable pair-bonding and high parental investment are likely to be advantageous strategies $[64,65]$.

This explanation may also apply to the more extreme case of patriarchal norms that regulate the place of females in the society, requiring them to behave very modestly, prohibiting certain behavior, preventing them to be educated and to fulfill a number of social positions, in the name of vaguely defined principles like "honor", "modesty" or "purity" [66]. Although these norms seem to organize the manipulation of female behavior by powerful males., anthropologists report significant support for such norms, including by some women [67]. Consistent with the mutualistic pathway described here, it may be the case that patriarchal rules, like puritanical norms, confer (distinct) advantages to men and women as they raise the cost of promiscuity. 


\section{6. $\underline{\text { References }}$}

1 Skorupski, J. (1975) Symbol and Theory. Cambridge University Press

2 Sperber, D. (1982) Apparently irrational beliefs. Rationality and relativism, 35-63

3 Sperber, D. (1975) Rethinking symbolism. Cambridge University Press

4 Pinker, S. (1997) How the mind works. Norton

5 Dawkins, R. (1976) The selfish gene. Oxford University Press

6 Thomson, W. (1958) The problem of tonality in pre-Baroque and primitive music.

Journal of Music Theory 2, 36-46

7 Huron, D.B. (2006) Sweet Anticipation: Music and the Psychology of

Expectation. MIT Press

8 Boyd, B. (2010) On the Origin of Stories - Evolution, Cognition, and Fiction.

Harvard University Press

9 Gottschall, J. (2012) The Storytelling Animal: How Stories Make Us Human.

Houghton Mifflin Harcourt

10 Gil-White, F.J. (2001) Are ethnic groups biological 'species' to the human brain?

Essentialism in our cognition of some social categories. Current Anthropology 42,

515-554

11 Hamilton, W.D. (1964) The genetical evolution of social behaviour I and II. $J$

Theor Biol 7, 1-16 and 17-52

12 West, S.A., et al. (2006) Social evolution theory for microorganisms. Nature

reviews microbiology 4,597

13 Hamilton, W.D. (1963) The evolution of altruistic behavior. The American

Naturalist 97, 354-356

14 Csibra, G. (2007) Teachers in the wild. Trends in Cognitive Sciences 11, 95-96

15 Mehr, S.A., et al. (2018) Form and function in human song. Current Biology 28, 356-368. e355

16 Dawson, L.L., ed (1998) Cults in Context. Readings in the Study of New Religious

Movements. Transaction Publishers

17 Boyer, P. (1994) The naturalness of religious ideas: A cognitive theory of

religion. University of California Press

18 Winkelman, M.J. (1990) Shamans and Other "Magico-Religious" Healers: A

Cross-Cultural Study of Their Origins, Nature, and Social Transformations. Ethos

18, 308-352

19 Singh, M. (2018) The cultural evolution of shamanism. Behavioral and Brain

Sciences 41

20 West, S.A., et al. (2007) Social semantics: altruism, cooperation, mutualism, strong reciprocity and group selection. Journal of Evolutionary Biology 20

21 Darwin, C. (1871) The descent of man, and selection in relation to sex. J. Murray 22 West-Eberhard, M.J. (1979) Sexual selection, social competition, and evolution.

Proceedings of the American Philosophical Society 123, 222-234

23 Wiedemann, D., et al. (2012) Evolutinary perscetives on sport and competition.

In Applied Evolutionary Psychology (Roberts, S.C., ed), pp. 290-309, Oxford

University Press

24 De Block, A. and Dewitte, S. (2009) Darwinism and the cultural evolution of

sports. Perspect Biol Med 52, 1-16 
25 Miller, G.F. (1999) Sexual selection for cultural displays. The evolution of culture, 71-91

26 Jolly, M. (1994) Kastom as Commodity: the Land Dive as Indigenous Rite

Spectacle in Vanuatu. In Culture, Kastom, Tradition: Developing Cultural Policy in

Melanesia (Lindstrom, L. and White, G.M., eds), pp. 131-146, Institute of Pacific

Studies, University of the South Pacific

27 Price, D.D., et al. (2008) A comprehensive review of the placebo effect: recent advances and current thought. Annu. Rev. Psychol. 59, 565-590

28 Bicchieri, C. (2006) The grammar of society : the nature and dynamics of social norms. Cambridge University Press

29 Lewis, D.K. (1969) Convention: a philosophical study. Harvard University Press 30 West, S.A. and Gardner, A. (2010) Altruism, spite, and greenbeards. Science 327, 1341-1344

31 Lehmann, L., et al. (2006) An evolutionary analysis of the relationship between spite and altruism. Journal of evolutionary biology 19, 1507-1516

32 Boyer, P. (2019) Informal Religious Activity Outside Hegemonic Religions: Wild Traditions and Their Relevance to Evolutionary Models. Religion, Brain \& Behavior 33 Lienard, P. and Boyer, P. (2006) Whence Collective Rituals? A Cultural Selection Model of Ritualized Behavior. American Anthropologist 108, 814-827

34 Winkelman, M.J. (1986) Magico-religious practitioner types and socioeconomic conditions. Behavior Science Research 20, 17-46

35 Woody, E. and Szechtman, H. (2011) Adaptation to potential threat: the evolution, neurobiology, and psychopathology. Neuroscience and Biobehavioral Reviews 35, 1019-1033

36 Gell, A. (1998) Art and Agency: An Anthropological Theory. Clarendon Press 37 Dutton, D. (2009) The Art Instinct: Beauty, Pleasure, \& Human Evolution. Oxford University Press

38 Lerdahl, F. and Jackendoff, R. (1985) A Generative Theory of Tonal Music. MIT Press

39 Tooby, J. and Cosmides, L. (1992) The psychological foundations of culture. In

The adapted mind: Evolutionary psychology and the generation of culture.

(Barkow, J.H., et al., eds), pp. 19-136, Oxford University Press

40 Tooby, J. and Cosmides, L., eds (2005) Conceptual Foundations of Evolutionary Psychology. John Wiley \& Sons Inc

41 Morin, O. (2016) How traditions live and die. Oxford University Press

42 Acerbi, A. (2016) A cultural evolution approach to digital media. Frontiers in

Human Neuroscience 10

43 Gray, R.D., et al. (2010) On the shape and fabric of human history. Philosophical

Transactions of the Royal Society B: Biological Sciences 365, 3923-3933

44 Shennan, S. (2011) Descent with modification and the archaeological record.

Philosophical transactions of the royal society B: Biological sciences 366, 10701079

45 Atkinson, Q.D. (2011) Phonemic diversity supports a serial founder effect model of language expansion from Africa. Science 332, 346-349

46 Boyd, R. and Richerson, P.J. (1985) Culture and the evolutionary process. University of Chicago Press

47 Henrich, J. and Gil-White, F.J. (2001) The evolution of prestige: Freely conferred deference as a mechanism for enhancing the benefits of cultural transmission.

Evolution \& Human Behavior 22, 165-196 
48 Claidière, N., et al. (2014) How Darwinian is cultural evolution? Philosophical Transactions of the Royal Society of London B: Biological Sciences 369

49 Sperber, D. and Claidière, N. (2006) Why modeling cultural evolution is still such a challenge. Biological Theory 1, 20-22

50 Lehmann, L. and Feldman, M.W. (2008) The co-evolution of culturally inherited altruistic helping and cultural transmission under random group formation.

Theoretical Population Biology 73, 506-516

51 Enquist, M., et al. (2007) Critical social learning: a solution to Rogers's paradox of nonadaptive culture. American Anthropologist 109, 727-734

52 Griffiths, T.L., et al. (2008) Theoretical and empirical evidence for the impact of inductive biases on cultural evolution. Philosophical Transactions of the Royal

Society B: Biological Sciences 363, 3503-3514

53 Smith, K. and Kirby, S. (2008) Cultural evolution: implications for understanding the human language faculty and its evolution. Philosophical Transactions of the

Royal Society B: Biological Sciences 363, 3591-3603

54 Kirby, S., et al. (2008) Cumulative cultural evolution in the laboratory: An experimental approach to the origins of structure in human language. Proceedings of the National Academy of Sciences 105, 10681-10686

55 Mar, R.A. and Oatley, K. (2008) The function of fiction is the abstraction and simulation of social experience. Perspectives on psychological science 3, 173-192 56 Tooby, J. and Cosmides, L. (2001) Does Beauty Build Adapted Minds? Toward an Evolutionary Theory of Aesthetics, Fiction and the Arts. SubStance 94/95, 6-27 57 Archer, J. (2011) Pet keeping: A case study in maladaptive behavior. The Oxford handbook of evolutionary family psychology, 281-296

58 Boyer, P. (2000) Functional Origins of Religious Concepts: Conceptual and Strategic Selection in Evolved Minds [Malinowski Lecture 1999]. Journal of the Royal Anthropological Institute 6, 195-214 59 Ostrom, E. (2005) Understanding institutional diversity. Princeton University Press

6o Fessler, D.M.T. (2002) Windfall and socially distributed willpower: The psychocultural dynamics of rotating Savings and Credit Associations in a Bengkulu Village. Ethos 30, 25-48

61 Baumard, N. (2015) Evolutionary psychology and public policy. In The Handbook of Evolutionary Psychology, Second Edition, pp. 1123-1142, Wiley

62 Kurzban, R., et al. (2010) Sex, drugs and moral goals: reproductive strategies and views about recreational drugs. Proceedings of the Royal Society B: Biological Sciences 277

63 Kurzban, R. (2012) Why Everyone (Else) Is a Hypocrite: Evolution and the Modular Mind. Princeton University Press

64 Baumard, N. and Chevallier, C. (2015) The nature and dynamics of world religions: a life-history approach. Proceedings of the Royal Society B: Biological Sciences 282, 1-9

65 Baumard, N., et al. (2015) Increased Affluence Explains the Emergence of Ascetic Wisdoms and Moralizing Religions. Current Biology 25, 10-15 66 Afkhami, M. (1995) Faith and Freedom: Women's Human Rights in the Muslim World. I.B. Tauris

67 Abu-Lughod, L. (1986) Veiled sentiments: Honor and poetry in a Bedouin society. University of California Press 